\title{
The influence of gravity on REM sleep
}

\author{
This article was published in the following Dove Press journal: \\ Open Access Animal Physiology \\ 22 May 2015 \\ Number of times this article has been viewed
}

\section{Alain A Gonfalone' \\ Sushil K Jha ${ }^{2}$ \\ 'European Space Agency, Paris, France; \\ ${ }^{2}$ School of Life Sciences, Jawaharlal \\ Nehru University, New Delhi, India}

Correspondence: Alain A Gonfalone LOGON, I 28 Chemin de l'Ousiere, St Marcellin les Vaison 84II0, France Tel +33633139824

Email alain.gonfalone@wanadoo.fr

\begin{abstract}
It is suggested that environmental variables, and gravity in particular, are the main determinants of sleep duration. Assuming that the rapid eye movement (REM) sleep state depends on the influence of gravity allows a better understanding of sleep across the animal world. This paper is based on numerous results already published on sleep behaviors, sleep postures, sleep durations, and the weights of many species. The difference between the sleep behavior of aquatic animals and terrestrial mammals is explained by the effect of gravity in different environments: ocean or land. Archimedes' principle applied to aquatic animals shows that their weight is minimal and this may explain the lack of REM sleep. The fact that cats or rats in unsafe positions above water do not experience REM sleep is explained by the fear of atonia, a complete relaxation of the antigravity muscles, which happens during REM sleep, completing the process of reduced sensitivity to the environment: light, sound, contact, etc. Furthermore, a very clear dependence of sleep duration on weight is obtained when plotting the data for 76 terrestrial mammalian species, showing that sleep and gravity are related. Another dependence of sleep duration, on gestation time, is presented, and this shows the difficulty of interpreting sleep and its relation to a single parameter.
\end{abstract}

Keywords: weight, atony, mammal, dream

\section{Introduction}

This paper explains some characteristics of sleep across the animal world using the assumption that sleep and gravity are related. Studies related to analyses of sleep are numerous. Although it has been proposed that sleep has a universal physiological function across species, there is no consensus as to what that function might be. ${ }^{1}$ Sleep duration in mammals has been extensively studied, in particular by Siegel. ${ }^{2}$ To our knowledge, that is the only study in which body mass has been taken into account. The author provides graphs for carnivores, herbivores, and omnivores and observes that sleep amount is an inverse function of body mass across all terrestrial mammals. Another paper, by Madan and $\mathrm{Jha}^{3}{ }^{3}$ compiled total sleep time (TST) and rapid eye movement (REM) sleep duration for 76 mammals. However, there was no attempt to compare sleep duration with weight. This paper shows that, beyond the results obtained by Siegel, ${ }^{2}$ an obvious conclusion is that the amount of REM is also related to weight or, using a more fundamental physical quantity, gravity. Gravity, together with light, sound, gases, liquids, and solids, gives us the different sensations coming from our environment. These sensations are attenuated during the sleep period and the sensation of gravity is reduced via the atonia of the muscles. It is proposed that atonia is the way the body reacts to reduce the effort imposed on muscles by gravity. 


\section{Methods}

This research paper is not based on either animal observations or neurophysiological measurements. It is based on an extensive review of already published results, which all confirm that sleep and gravity are related. Intense use of the Internet using the search words "REM sleep" and "mammals", in particular, Google and Wikipedia, led us to the most relevant research papers, which were acquired when necessary and analyzed carefully. In spite of this, some omissions may have occurred, but it is thought that enough convincing evidence has been obtained from the references listed at the end.

First, it is necessary to clarify the subtle, but important, difference between mass and weight. As weight is the product of mass and gravity, weight is a characteristic of terrestrial animals only. It is the force by which a body is attracted to Earth. However, the situation in water is different. The mass of a fish or other aquatic animal can be high, such as with a sperm whale with a mass of 60 tons or more; ${ }^{4}$ nevertheless, the whale's weight is certainly very small, because of the buoyancy due to Archimedes force.

The theory of evolution suggests that terrestrial animals evolved from aquatic species that left the ocean to venture onto land. There are differences between the aquatic environment and the land environment. It is admitted that lungs developed to respire oxygen and that warm blood took care of the variations of temperature. The limbs developed for locomotion and to support the animal's body weight against gravity. The biomechanical demands of aquatic and terrestrial locomotion are vastly dissimilar, and are reflected in different energy costs for swimming and walking or running.

One result from Jouvet, ${ }^{4}$ and limited results from Madan and Jha, ${ }^{3}$ will be used here and analyzed against gravity by looking at the way gravity influences the observations. The paper by Madan and $\mathrm{Jha}^{3}$ contains data for over 76 species. The curves obtained using a regression analysis show a clear trend: the heavier animals have less REM sleep than the lighter ones. This trend was previously observed, ${ }^{2}$ but there was no attempt to relate this trend to gravity. Other correlations between sleep and lifetime ${ }^{5}$ or predatory danger ${ }^{6}$ have been established: these authors identified traits to be investigated in future field studies and comparative studies.

\section{Results}

In the following sections, the effect of weight on REM sleep of the different classes of animals is analyzed. Paradoxically, it is easier to understand what triggers REM sleep in mammals rather than explaining what prompts the beginning of non-REM (NREM) sleep.

\section{Mammals}

Despite the differences, human sleep behavior can provide some insights into the sleep patterns of other species. Most mammals carry their body weight on four limbs; equilibrium is more difficult to control on two legs, as the center of gravity must be above the sustentation polygon, and the behavior of the human species should show a greater dependence on gravity than that of four-legged animals.

It is appropriate to analyze the sleep behavior of humans (including newborns) with respect to their weight. Newborns and infants have a reflex, called the Moro reflex, which is a response to a sudden loss of support, when the infant feels as if it is falling. It appears that birth and exposure to gravity immediately produce an instinctive reflex in the human infant. Another reflex is the walking reflex, in which newborns move their legs as if walking, although they are not able to sustain the weight of their body at this early age.

A follow-up to the Moro reflex is the fear of falling, a natural fear typical of most humans and other mammals, to varying degrees of extremity. The fear of falling encompasses the anxieties accompanying the sensation and the possibly dangerous effects of falling. ${ }^{7}$ Studies on nonhuman subjects strongly support the theory of falling as an inborn fear. Gibson and Walk ${ }^{7}$ performed experiments with young chickens, turtles, rats, lambs, kittens, and puppies. The results were similar to those in human infants, although each animal behaved slightly differently according to the characteristics of its species. Based on the results of the animals tested, the findings indicate that the fear of falling is instilled in animals at a very young age, if not innate. Newborns are then aware of the possible effect of gravity: a fall.

Jouvet, ${ }^{4}$ a French scientist involved in sleep study, observed that a cat on a small platform in the middle of a pond of water does not experience REM sleep (Figure 1). This puzzling observation has been explained in the following way: the cat may enter into REM sleep but, because of atonia and the subsequent risk of falling, the cat refrains from REM sleep. Atonia is precisely the state obtained when all antigravity muscles are put at rest: during the whole wake period, these muscles are under tension and finally, during sleep, and in particular during REM sleep, they are put at rest. If sleep is a way to become momentarily detached or insensitive to the solicitations of the external world, the influence of light, sound, contact, odors, and tastes 


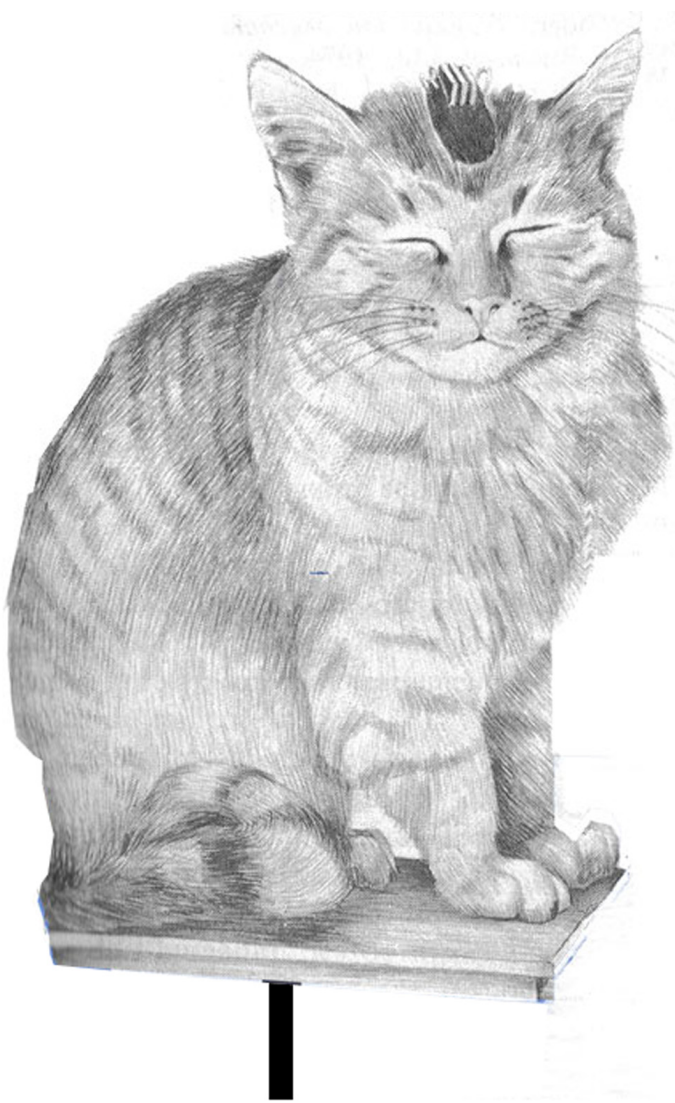

Figure I Jouvet observes that the cat above water has no REM sleep.

Notes: The lack of REM sleep can be explained by the occurrence of atonia during REM sleep and the subsequent fear of the cat of falling in the water.

Adapted from Un chat sur une plateforme au milieu d'une étendue d'eau in "Le Rêve”, prof. Jouvet in La Recherche en neurobiologie, Collectif, revue La Recherche, (C) Éditions du Seuil-La Recherche, 1977, coll. Points Sciences, 1988. [A cat on a platform in the middle of a body of water in "The Dream", prof. Jouvet in Research in neurobiology, Collective, magazine La Recherche, (c) Seuil-La Recherche, 1977 al. Points Sciences. 1988]. ${ }^{4}$

Abbreviation: REM, rapid eye movement.

(the five senses) are reduced successively, and, in addition, the decrease of the influence of gravity is shown by the atonia of most muscles. In the experiment of Jouvet, ${ }^{4}$ the cat cannot refrain from the fear of falling as long as it is not in a safe position, either on the ground or on a large surface that can carry its weight. In contrast, the cat does experience REM sleep when it lies down.

Sleep deprivation by the "disk-over-water" technique (which forces an animal to walk and provide an effort against gravity and thus wake up every time it falls asleep) is lethal to rats. ${ }^{8}$

A careful and very extensive literature review ${ }^{9}$ shows that almost all terrestrial mammals have to lie down to experience REM sleep. There are two exceptions: the bat and the three-toed sloth, which can sleep while hanging upside down. Animals such as horses and elephants can sleep on four legs; however, they only experience REM sleep if they lie down. Giraffes put their heads down on the ground when they undergo REM sleep. The explanation for this phenomenon is that, during the wake period, there is permanent control of the equilibrium and a great number of muscles participate in the maintenance of the upright posture, ie, in the legs, torso, neck, etc. When this is strongly reduced or ceases, REM sleep begins.

REM sleep occurs after an NREM sleep period when all sensations coming from the outside world - light, sound, contact, odor, and taste - are drastically reduced, and when the brain and the nervous system, via relaxed muscles, tend to decrease control of gravity as well. Vigilance against a possible fall is reduced, which can happen if the following conditions are met: a "preparatory" phase of NREM sleep and the feeling of a safe posture and position.

Table 1 and the associated graphs in Figure 2 show a clear dependence of REM sleep on weight. In agreement with a previous study, ${ }^{10}$ we found that REM and NREM sleep quotas exhibit similar correlations. As noted by Madan and $\mathrm{Jha}^{3}{ }^{3}$ the REM sleep duration represents a mean value of approximately $20 \%$ of the TST for almost all species.

The curves shown in Figure 2 include a range of weights, from a few grams to hundreds of kilograms. The sleep duration of the giant armadillo and the opossum are outside the cluster of points for other species. No explanation can be found for this unique behavior, as they are both mammals with no evident special traits. As mentioned before, these curves were obtained by Siegel, ${ }^{2}$ but only for TST, while here, the REM sleep duration also appears to depend on gravity. The only conclusion that can be drawn from these curves is that REM sleep depends on gravity. This means that sleep and gravity are not independent of each other and sleep is affected by one of the fundamental components of our environment: gravity.

As shown in the Discussion section, if sleep duration is compared with the gestation period of terrestrial mammals, a better trend curve is obtained. Further study of the interrelationship between sleep, weight, and gestation is needed.

\section{Semi-aquatic mammals}

For REM sleep to occur, terrestrial animals have to reduce their vigilance against a fall, but this rule applies differently for semi-aquatic animals. For example, the case of seals is very specific and is described in detail in a paper by Siegel:

When in the water, the fur seal has an extremely small amount of REM sleep [...] Surprisingly, when the fur seal 
Table I Sleep depends on gravity in all terrestrial mammal species

\begin{tabular}{|c|c|c|c|c|}
\hline Species & $\begin{array}{l}\text { REM } \\
\text { (h) }\end{array}$ & $\begin{array}{l}\text { Total } \\
\text { sleep }(h)\end{array}$ & $\begin{array}{l}\text { Log } \\
\text { Weight }\end{array}$ & $\begin{array}{l}\text { Weight } \\
\text { (kg) }\end{array}$ \\
\hline Horse & 0.79 & 2.9 & 2.54 & 350 \\
\hline Cow & 0.75 & 4.0 & 2.54 & 350 \\
\hline Pig & 2.63 & 9.0 & 2.26 & 180 \\
\hline Human & 1.9 & 8.0 & 1.90 & 80 \\
\hline Sheep & 0.57 & 3.9 & 1.90 & 80 \\
\hline Goat & 0.71 & 5.4 & 1.85 & 70 \\
\hline Chimpanzee & 1.62 & 10.8 & 1.78 & 60 \\
\hline Giant armadillo & 6.1 & 18.1 & 1.48 & 30 \\
\hline Olive baboon & 1.39 & 9.8 & 1.38 & 24 \\
\hline Siberian musk deer & 0.74 & 10.2 & 1.20 & 16 \\
\hline Dog & 1.55 & 8.6 & 1.18 & 15 \\
\hline Barbary macaque & 1.07 & 11.8 & 1.16 & 14.5 \\
\hline Yellow baboon & 0.78 & 9.9 & 1.15 & 14 \\
\hline Hamadryas baboon & 1.26 & 9.8 & 1.15 & 14 \\
\hline Guinea baboon & 0.54 & 9.0 & 1.15 & 14 \\
\hline Patas monkey & 0.86 & 10.9 & 1.06 & 11.5 \\
\hline Stump-tailed macaque & 1.52 & 9.5 & 0.98 & 9.5 \\
\hline Vervet monkey & 0.6 & 10.3 & 0.93 & 8.5 \\
\hline Pig-tailed macaque & 1.06 & 9.6 & 0.90 & 8 \\
\hline Red fox & 2.4 & 9.8 & 0.78 & 6 \\
\hline Rhesus macaque & 0.98 & 9.0 & 0.74 & 5.5 \\
\hline Bonnet macaque & 1.05 & 9.2 & 0.72 & 5.3 \\
\hline Nine-banded armadillo & 3.56 & 18.0 & 0.65 & 4.5 \\
\hline $\begin{array}{l}\text { Brown-throated three-toed } \\
\text { sloth }\end{array}$ & 1.19 & 10.5 & 0.60 & 4 \\
\hline Cat & 3.22 & 13.2 & 0.60 & 4 \\
\hline Rabbit & 1.09 & 8.4 & 0.60 & 4 \\
\hline Southern opossum & 5.65 & 19.4 & 0.60 & 4 \\
\hline Tree hyrax & 0.5 & 4.9 & 0.54 & 3.5 \\
\hline Yellow-spotted hyrax & 0.91 & 5.3 & 0.54 & 3.5 \\
\hline Rock hyrax & 0.55 & 4.9 & 0.54 & 3.5 \\
\hline Yellow-bellied marmot & 1.81 & 17.4 & 0.54 & 3.5 \\
\hline Virginia opossum & 7.34 & 16.3 & 0.54 & 3.5 \\
\hline Brushtail possum & 1.68 & 13.7 & 0.51 & 3.25 \\
\hline Mongoose lemur & 0.36 & 11.9 & 0.43 & 2.7 \\
\hline Common tenrec & 2.34 & 15.6 & 0.40 & 2.5 \\
\hline Black lemur & 0.84 & 9.7 & 0.38 & 2.4 \\
\hline Common genet & 1.3 & 6.1 & 0.34 & 2.2 \\
\hline Long-nosed potoroo & 0.62 & 10.7 & 0.18 & 1.5 \\
\hline Senegal galago & 0.87 & 7.8 & 0.18 & 1.5 \\
\hline Guinea pig & 1.06 & 8.6 & 0.18 & 1.5 \\
\hline African giant pouched rat & 2 & 8.3 & 0.10 & 1.25 \\
\hline Ferret & 5.86 & 14.5 & 0.08 & 1.2 \\
\hline Large hairy armadillo & 4.48 & 20.4 & 0.00 & I \\
\hline Western European hedgehog & 2.88 & 10.1 & 0.00 & I \\
\hline Northern night monkey & 1.82 & 17.0 & 0.00 & I \\
\hline Brandt's hedgehog & 2.82 & 10.3 & -0.12 & 0.75 \\
\hline Common squirrel monkey & 1.03 & 9.1 & -0.12 & 0.75 \\
\hline Mountain beaver & 2.45 & 14.4 & -0.15 & 0.7 \\
\hline Arctic ground squirrel & 3.38 & 16.1 & -0.15 & 0.7 \\
\hline Lutrine opossum & 6.53 & 19.4 & -0.30 & 0.5 \\
\hline Hispid cotton rat & 1.48 & 11.3 & -0.31 & 0.485 \\
\hline Chinchilla & 1.55 & 12.5 & -0.35 & 0.45 \\
\hline Norway rat & 2.58 & 13.2 & -0.46 & 0.35 \\
\hline Lesser mole rat & 2.39 & 10.6 & -0.46 & 0.35 \\
\hline
\end{tabular}

Table I (Continued)

\begin{tabular}{|c|c|c|c|c|}
\hline Species & $\begin{array}{l}\text { REM } \\
\text { (h) }\end{array}$ & $\begin{array}{l}\text { Total } \\
\text { sleep (h) }\end{array}$ & $\begin{array}{l}\text { Log } \\
\text { Weight }\end{array}$ & $\begin{array}{l}\text { Weight } \\
\text { (kg) }\end{array}$ \\
\hline Common marmoset & 1.6 & 9.5 & -0.60 & 0.25 \\
\hline $\begin{array}{l}\text { Golden-mantled ground } \\
\text { squirrel }\end{array}$ & 2.76 & 14.5 & -0.60 & 0.25 \\
\hline Degu & 0.52 & 6.9 & -0.63 & 0.235 \\
\hline Common tree shrew & 2.59 & 15.8 & -0.72 & 0.19 \\
\hline $\begin{array}{l}\text { Thirteen-lined ground } \\
\text { squirrel }\end{array}$ & 3.41 & 13.8 & -0.72 & 0.19 \\
\hline Belding's ground squirrel & 3.01 & 15.8 & -0.90 & 0.125 \\
\hline Kangaroo rat & 2.72 & 16.0 & -0.92 & 0.12 \\
\hline Golden hamster & 3.51 & 15.0 & -0.96 & 0.11 \\
\hline House shrew & 2 & 12.8 & -1.00 & 0.1 \\
\hline Siberian chipmunk & 2.94 & 12.2 & -1.00 & 0.1 \\
\hline Gray mouse lemur & 1.37 & 14.3 & -1.15 & 0.07 \\
\hline Collared lemming & 3.19 & 15.2 & -1.15 & 0.07 \\
\hline Star-nosed mole & 2.17 & 10.3 & -1.26 & 0.055 \\
\hline Eastern mole & 2.11 & 8.5 & -1.30 & 0.05 \\
\hline Mongolian jird & 2.18 & 13.1 & -1.30 & 0.05 \\
\hline Mexican volcano mouse & 1.81 & 17.3 & -1.30 & 0.05 \\
\hline Djungarian hamster & 2.07 & 14.3 & -1.49 & 0.032 \\
\hline Blind mole rat & 1.9 & 12.4 & -1.49 & 0.032 \\
\hline Northern short-tailed shrew & 2.3 & 14.9 & -1.74 & 0.018 \\
\hline Big brown bat & 3.9 & 19.7 & -1.74 & 0.018 \\
\hline House mouse & 1.26 & 13.2 & -1.77 & 0.017 \\
\hline Little brown bat & 1.99 & 19.9 & -2.10 & 0.008 \\
\hline Little pocket mouse & 3.15 & 20.1 & -2.10 & 0.008 \\
\hline Least shrew & 1.4 & 9.1 & -2.30 & 0.005 \\
\hline
\end{tabular}

Notes: For the sake of simplicity, aquatic mammal data are not included in the table. Abbreviation: REM, rapid eye movement.

moves onto land after spending weeks in the water, a change

in its sleep structure occurs immediately. ${ }^{11}$

Seals in the water do not have to support their weight and consequently do not experience REM sleep; however, once on land, the seal's sleep behavior is similar to the sleep behavior of terrestrial mammals. This phenomenon would also explain the lack of rebound in REM sleep, as the need for REM sleep does not exist in water.

Other semi-aquatic mammals show unihemispheric slow-wave sleep, a negligible amount or complete absence of REM sleep, and a varying degree of movement during sleep associated with body size. The need for breathing and the need to stay afloat may prevent the nervous system from reaching the same state of relaxation as for the terrestrial mammals, hence the semi-aquatic mammals do not experience much REM sleep.

\section{Birds}

Contrary to popular belief, birds hardly ever sleep in nests. Most birds have to stand, sometimes on one or two legs. In principle, during sleep, they also have to support their weight 


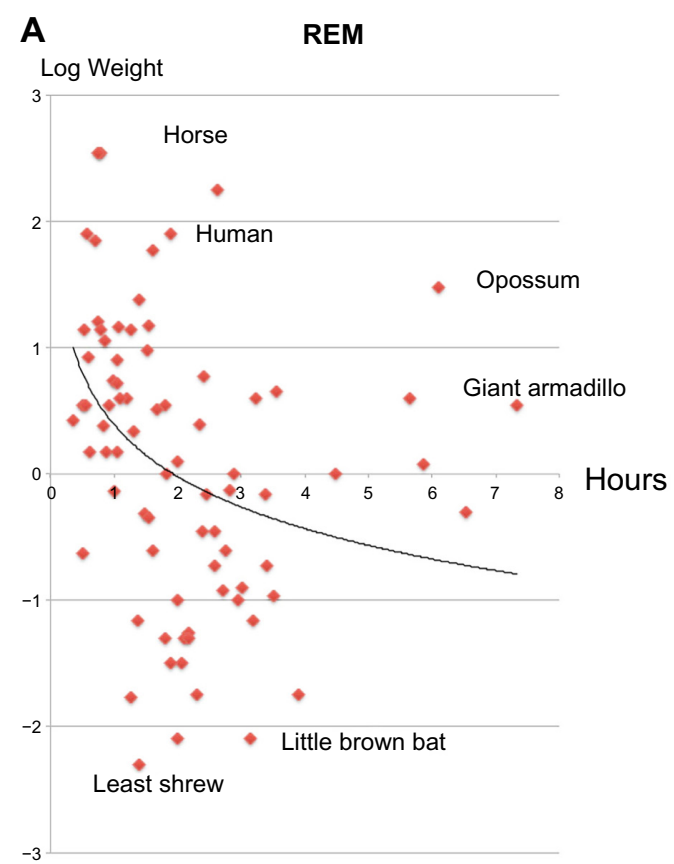

Log weight against duration of REM sleep

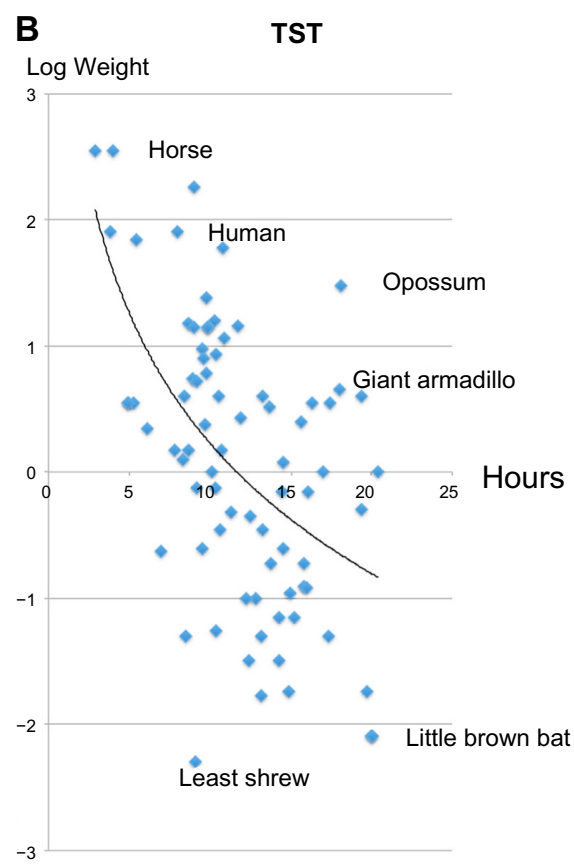

Log weight against TST

Figure 2 Relation between weight and sleep on a semi-logarithmic scale.

Notes: At this stage, the curves indicate that both REM sleep time (A) and total sleep time (TST) (B) depend on gravity. There are many species which show sleep behavior outside the cloud of points: this is particularly true for the armadillo and the opossum. Abbreviation: REM, rapid eye movement.

above ground like mammals. A peculiarity that birds share with aquatic mammals is the ability for unihemispheric sleep. A complete relaxation of the body and reduced vigilance from the nervous system are hardly possible. When using the data collected by Campbell and Tobler, ${ }^{12}$ the NREM sleep duration shows a slight trend indicating that heavy birds sleep more than lighter birds, if the penguin and the ostrich, the two non-flying birds (also the heaviest) are excluded from the graph. This result based on only 20 species is hardly convincing, and much more data on bird sleep are necessary before a conclusion can be drawn. Another research paper, by Roth et al, states: "We failed to find significant relationships even between NREM and REM sleep and body mass, brain mass, or basal metabolic rate, which are among the strongest relationships observed in mammalian studies". ${ }^{13}$

\section{Reptiles and amphibians}

These classes do not lend themselves easily to sleep studies. Papers on their sleep are not as numerous as for mammals. The amount of sleep may depend on the presence of limbs to carry the body.

Some reptiles, such as snakes, move on the ground and hardly have to support their weight. For some lizards, the limbs do not support the weight of the body but are used mostly for propulsive locomotion. Several studies indicate that frogs and some reptiles do not sleep, engaging only in restful waking. In an online article, Wilkerson states:

Some REM characteristics have been found in reptiles, including chameleons, desert iguanas and caimans. But the experiments all had problems that have left the question open. ${ }^{14}$

For the three classes, birds, reptiles, and amphibians, our assumption on the influence of gravity on sleep does not give conclusive results, although the few arguments presented above would indicate that animals of these classes do not have to spend energy or effort to carry the weight of their body in a manner similar to mammals.

\section{Fishes}

As said before, fishes benefit from neutral buoyancy. Archimedes force provides a push upward and gravity tends to pull the mass downward, and they weigh nothing or very little in the water as they can easily remain at a fixed depth and their horizontal displacement requires modest effort. It does not mean that gravity does not exist for fishes. Although it is a mammal, the sperm whale, with the contraction of its thoracic cage and the reduction of the volume of its spermaceti gland, can dive, or under the 
influence of gravity fall, to a depth of 3,000 m. Fishes may show sleep-like periods, but no REM sleep has ever been observed in these species.

From the sleep patterns of the semi-aquatic mammals and birds, the unihemispheric sleep corresponds to a vigilance from one brain hemisphere, against either drowning, asphyxia, predation, or other risks.

\section{Discussion}

\section{Gestation influence on sleep duration}

In the paragraphs above, the authors have indicated a possible relation between gravity and REM sleep. The conclusion helps understand why fishes with no weight do not have REM sleep while terrestrial mammals do have REM sleep.

The curves in Figure 2 showing the sleep duration against weight have been established following the study of Siegel. ${ }^{2}$
A clear conclusion deduced from Figure 2 is that heavier species sleep less and that sleep depends on gravity.

But these curves lend themselves to many comments and criticisms and cannot be easily interpreted. Many species seem to have behavior that does not follow the curves.

A better way to present the sleep duration is to use gestation time as another variable. Curves are now presented in Figure 3, associating a small image representing the species close to the data point. Most of the discrepancies shown in Figure 2 have now disappeared and the correlation between the variables is higher. The data are taken from the very complete review paper by Lesku et al. ${ }^{15}$ These authors correlated the sleep duration with the brain mass of the species considered. The data given in their paper have been rigorously included in our graph, and only the semi-aquatic mammals have been excluded from the collection of points. A more careful analysis of these species is needed.

\section{Gestation \\ Days}

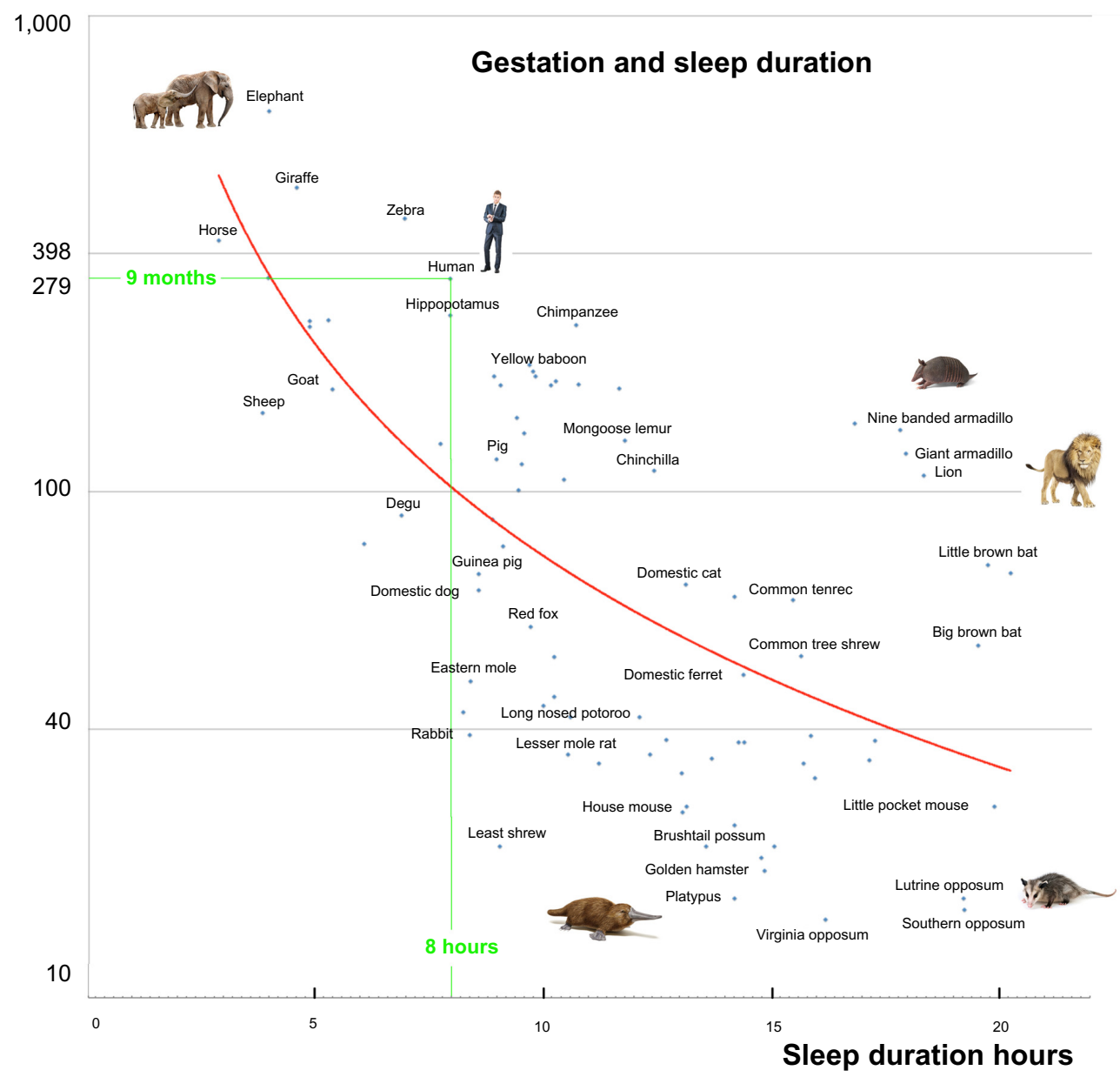

Figure 3 Relation between gestation time and sleep duration on a semi-logarithmic scale.

Notes: Many of the variations and the spreading of points of Figure 2 have been reduced. This shows that both gravity and gestation are related to sleep duration. 
Data for the platypus ${ }^{16}$ have been added and show that the gestation time is a better parameter than weight if one wants to understand the long sleeping time of the platypus. Data for the opossums are now in line with the data from other species.

The case of the armadillos is interesting. The data have been taken from the very complete paper from Lesku et al ${ }^{15}$ without any alteration. A closer look at the fertilization phenomena of the armadillo ${ }^{17}$ shows that this species has a delayed implantation of the egg in the womb of the female mother and that the gestation is in fact shorter than indicated by Lesku et al. ${ }^{15}$ If, on the curve, the gestation time is lowered by a factor of 2 , then the armadillo species show a behavior similar to other species.

For some time, researchers have been aware that pods of sperm whales may sleep for short periods, assuming a vertical position with their heads just below or at the surface. A 2008 study published in Current Biology recorded evidence that whales may sleep with both sides of the brain. ${ }^{18}$ It appears that some whales may fall into a deep sleep for about $7 \%$ of the time, most often between $6 \mathrm{pm}$ and midnight. The gestation period of the sperm whale of 14 to 16 months is in line with a small amount of sleep.

The lion has a very long sleep time. This follows the finding of Siegel for carnivores, ${ }^{2}$ and, up to now, no valid explanation, based on the present assumptions, could be found.

These curves do not invalidate previous findings shown in Figure 2. The gestation time of heavier species is longer than that of smaller species.

In an online article, Wilkerson quotes Siegel ${ }^{14}$ who cites Zeplelin and Jouvet-Mounier on this theory: "Zepelin showed that immaturity at birth is the single best predictor of REM sleep time throughout life". A degree of maturity of a newborn individual may depend on its time in gestation and may show a varying adaptation to the environment. The amount of sleep needed throughout its life is then a function of this adaptation at birth and sleep can be viewed as a state of adaptive inactivity.

\section{Conclusion}

Sleep duration is depending on the gestation length and REM sleep depends on the gravity.

The duration of sleep seems to compensate for the incomplete maturity of the brain after gestation. Every night is probably used to reprogram the features specific to each species.

Nonetheless, sleep and its functions remain opaque. It is the fate of the terrestrial animals to face the environment of the Earth on which they have to evolve. Light, sound, gases, liquids, and solids are part of this environment, but the impalpable gravity is omnipresent, and sleep may be the price to pay to live in the presence of gravity.

\section{Acknowledgments}

AA Gonfalone is a former staff of the European Space Agency where he was working in the Microgravity Department. Thanks to the many astronauts of the European Astronaut Corps whose flights have triggered the reflection about the influence of gravity in our daily lives.

\section{Author contributions}

SK Jha provided the extensive data bank for REM sleep and TST for the 76 species and raised the question of REM sleep absence in fishes. All authors contributed toward data analysis, drafting and revising the paper and agree to be accountable for all aspects of the work.

\section{Disclosure}

The authors report no conflicts of interest in this work.

\section{References}

1. Siegel JM. Sleep viewed as a state of adaptive inactivity. Nat Rev Neurosci. 2009;10(10):747-753.

2. Siegel JM. Clues to the functions of mammalian sleep. Nature. 2005;437:1264-1271.

3. Madan V, Jha SK. Sleep alterations in mammals: did aquatic conditions inhibit rapid eye movement sleep? Neurosci Bull. 2012;28: 746-758.

4. Jouvet M. Le rêve [The dream]. In: La Recherche en neurobiologie [Research in Neurobiology]. Editions du Seuil La Recherche, editor. Paris: 1977:126. French.

5. Zepelin H, Rechtschaffen A. Mammalian Sleep, Longevity, and Energy Metabolism. In: Brain Behaviour and Evolution. KARGER Medical and Scientific Publishers 1974;10:447-470.

6. Allison T, Cicchetti VD. Sleep in mammals: ecological and constitutional correlates. Science. 1976;194:732-734.

7. Gibson EJ, Walk RD. The "visual cliff." Sci Am. 1960;202:64-71.

8. Rechtschaffen A, Bergmann BM. Sleep deprivation in the rat by the disk-over-water method. Behav Brain Res. 1995;69:55-63.

9. Naish D. Sleep behaviour and sleep postures. Tetrapod Zoology. Available from: http://scienceblogs.com/tetrapodzoology/2008/09/15/ natural-history-of-sleep. Accessed March 29, 2015.

10. Capellini I, Barton RA, McNamara P, Preston BT, Nunn CL. Phylogenetic analysis of the ecology and evolution of mammalian sleep. Evolution. 2008;62:1764-1776.

11. Lyamin OI, Mukhametov LM, Siegel JM. Relationship between sleep and eye state in Cetaceans and pinnipeds. Arch Ital Biol. 2004; 142(4):557-568

12. Campbell SS, Tobler I. Animal sleep: a review of sleep duration across phylogeny. Neurosci Biobehav Rev. 1984;8:269-300.

13. Roth TC 2nd, Lesku JA, Amlaner CJ, Lima SL. A phylogenetic analysis of the correlates of sleep in birds. J Sleep Res. 2006;15:395-402.

14. Wilkerson R. The Evolution of REM Dreaming: New Research Includes All Mammals [webpage on the Internet]. Electric Dreams. 2003;10(1). Available from: http:/www.improverse.com/ed-articles/richard_wilkerson_2003_jan_evolution.htm. Accessed April 14, 2015. 
15. Lesku JA, Roth TC, Rattenborg NC, Amlaner CJ, Lima SL. Phylogenetics and the correlates of mammalian sleep: a reappraisal. Sleep Med Rev. 2008;12:229-244.

16. Siegel JM, Manger PR, Nienhuis R, Fahringer HM, Shalita T, Pettigrew JD. Sleep in the platypus. Neuroscience. 1999;91(1):391-400.
17. Hamlett GWD. Delayed implantation and discontinuous development in the mammals. $Q$ Rev Biol. 1935;10:435-436.

18. Miller PJ, Aoki K, Rendell LE, Amano M. Stereotypical resting behavior of the sperm whale. Curr Biol. 2008;18:R21-R23.

\section{Publish your work in this journal}

Open Access Animal Physiology is an international, peer-reviewed, open access journal publishing original research, reports, reviews and commentaries on all areas of animal physiology. The manuscript management system is completely online and includes a very quick and fair peer-review system. Visit http://www.dovepress.com/ testimonials.php to read real quotes from published authors. 